\title{
Assessment of land surface temperature variation over Rusafa side of Baghdad city, Iraq
}

\author{
Ayad Beg ${ }^{1, *}$ \\ ${ }^{1}$ College of Education, Department of Geography, Mustansiriyah University, Baghdad, Iraq
}

\begin{abstract}
The current study is concerned with Rusafa side of Baghdad city, which extends on 362 square kilometres and is inhabited by 3738371 people. It suffers from population growth, which led to decline in municipal services and rising of land surface temperature (LST) during the summer season. The current study aims to assess the spatial and temporal variation of LST using different dated satellite images of Landsat 4, 7 and 8 at path 168 and raw 037 during July 16, 1989, April 25, 2000, April 26, 2006, and May 31, 2016. Eight analysis models which were built using ERDAS 2014 software are used to calculate the LST parameters; while the land use/land cover (LULC) types are classified using ENVI v.5.3 software. The maximum surface temperature recorded at barren lands are between 26 and $41{ }^{\circ} \mathrm{C}$, while at vegetation cover ranging from 25 to $34{ }^{\circ} \mathrm{C}$ and an inverse correlation are recorded between LST and NDVI ranging from -0.5 to -0.81 . The built-up area was increased by $23 \%$, whereas open spaces and vegetation cover are decreased by $16 \%$ and $6 \%$ respectively all that consequently will make the environment of the study area prone to be warmer.
\end{abstract}

\section{Introduction}

Evolution of Land Surface Temperature (LST) based on remote sensing data depends on the spatial resolution of the sensors, as well as modelling process requiring a collection of mathematical equations for calculation the solar radiation parameters, vegetation indices and land surface temperature. The spatial analysis, includes three elements: cartographic modelling represent mapping and their related calculations, mathematical modelling, based on the spatial interaction and relationships between the objects in the model according to the mathematical equations, and finally statistical analysis modelling, which use the appropriate spatial statistical analysis [1]. The land surface temperature (LST) derived from low spatial resolution imagery is termed as urban heat island (UHI), and correspond closely with canopy layer heat island [2]. LST is important in direct estimation of long wave fluxes and indirect estimation of latent and sensible heat fluxes, and other applications including geology, hydrology, vegetation monitoring and global circulation model and the use of thermal infrared of satellite imageries are very attractive in global access and uniform estimation of surface temperatures [3]. Land surface temperature (LST) is important in understanding the dynamic of urban thermal environment and it is a function of four parameters i.e., albedo, emissivity, the thermal properties of construction materials, composition and structure of urban canopy, and correspond closely to the spatial variation of land use/land cover [2]. The material properties i.e., heat capacity; thermal conductivity and thermal inertia are the main factors controlling the spatial variation of LST [4]. Nichol [5] referred to the advantage of remote sensing in analysis of urban heat island by providing dense grid of time synchronized surface temperature over the whole city. Uneven distribution of trees and vegetation cover in the city lead to uneven distribution of ecosystem services and community benefits, in fact, the tree cover in the city can be considered as a social justice issue, because a $5 \%$ reduction in tree cover can rise air temperature by $1-2$ ${ }^{\circ} \mathrm{C}[6]$.

Rusafa side of Baghdad city is characterized by high population density; population growth and spread of slums after 2003 resulting in illegal expansion on land especially vegetation cover and landscapes, consequently leading to a change in the physical characteristics of the city canopy. In fact, since Iraqi cities are mostly surrounded by barren or semi barren land, so during the summer season, impact of the heat island is imperceptible between the city and its surrounding areas; hence, the land surface temperature is the main factor impacting the city climate. The study area is characterized by high temperature during summer season, induced negative impact on the ecosystem of the city, many citizens are exposed to diseases and stresses caused by rising temperature, as well as the activity of organisms and rodents fertility are increased during summer, accompanied by appearance of viruses that cause diseases. The current study aims to a). Assessment of the temporal and spatial variation of land surface temperature using remote sensing and geographic

\footnotetext{
*Corresponding author: aafbeg64@uomustansiriyah.edu.iq
} 
information systems techniques based on Landsat 4, 7 and 8 satellite imageries acquired during four periods between 1989 and 2016, b). Building models using ERDAS 2014 to calculate the spectral radiance, reflectance, albedo, vegetation indices, and land surface temperature, c). Classification of land use/ land covers using ENVI v.5.3 software, d). Production of LULC and LST distribution maps using ArcGIS v 10.3, and e). Point out the statistical relation between LST and NDVI.

\section{Description of study area}

Baghdad is a capital city and located in the central part of Iraq; divided by Tigris river into two sides - Rusafa on East and Karkh on West. The current study focusing on Rusafa side which extends on an area of 362 square kilometers and bounded by latitudes $33^{\circ} 13^{\prime}, 33^{\circ} 27^{\prime} \mathrm{N}$, and longitudes $44^{\circ} 17^{\prime}$, 44 $33^{\prime} \mathrm{E}$ (Fig. 1), and inhabited by about (3738371) million people, with population density of about (10326) people/ sq km. Administratively, the area composed of (8) municipal units and has a road network with a length of 3814 kilometres.

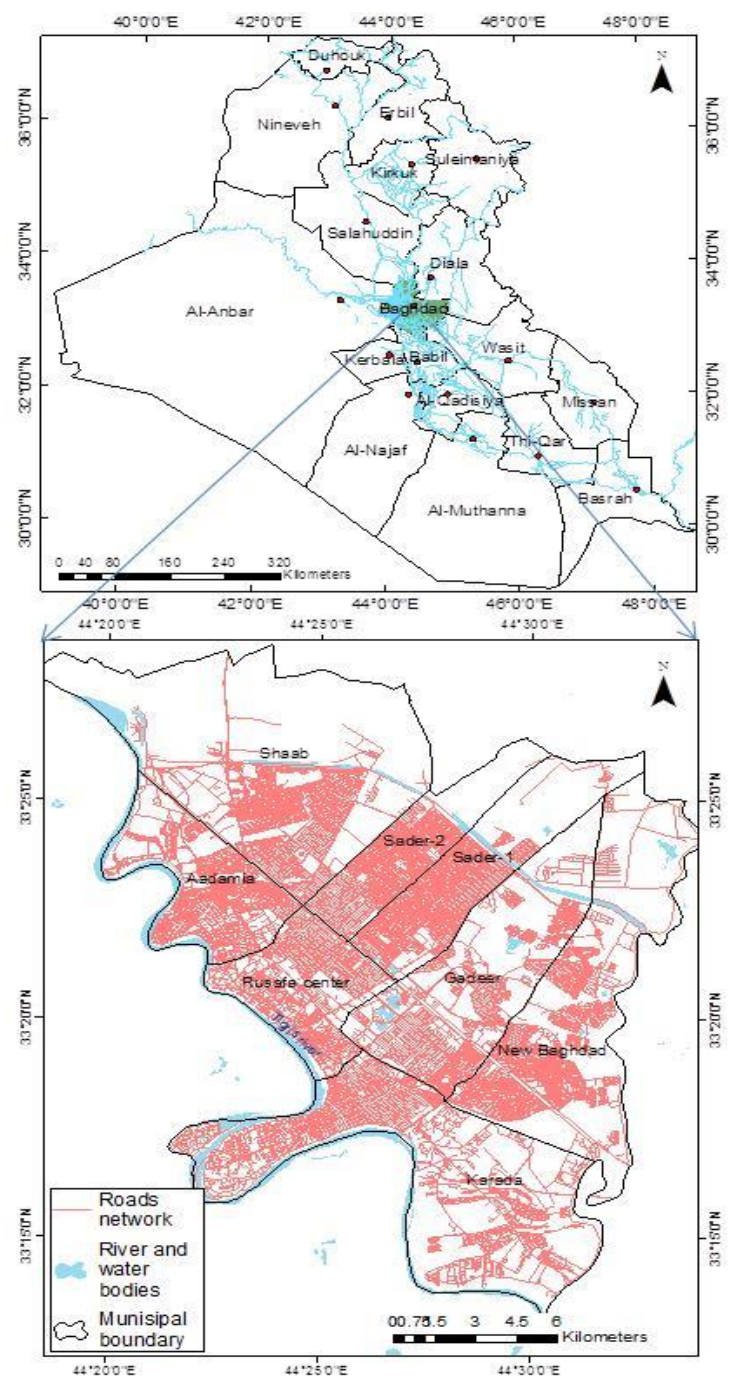

Fig. 1. Location of study area.

\section{Methodology}

The analysis method involved the collection of satellite images, selection of necessary software for image processing and presentation of the results, and gathering of the surface temperature above different land use/land cover types by in-situ measurements, collection the mathematical bases required for modelling, building the analysis models to calculate the spectral radiation parameters, vegetation cover indices, and land surface temperature.

\subsection{Data and processing software}

The most important data used in the analysis are remote sensing data of Landsat 4, 7 and 8 satellites (raw 037, path 168) acquired on 16 July 1989, 25 April 2000, 26 April 2006 and 31 May 2016. The satellite imageries are downloaded from the website https://earthexplorer.usgs.gov. To validate the analysis carried out from satellite imageries, field measurements of the contact surface temperature and at a height of half a meter above different types of land use /land cover in the city was carried out. Digital image processing models were prepared using the ERDAS 2014 software, while land use/ land cover types were classified using spectral angle mapper (SAM) method executed on ENVI 5.3 software.

The spatial distribution maps for different variables and calculation of statistical parameters of LSTs according to land cover classes were performed using ArcGIS 10.3. The MICROSOFT EXCEL program was used to create tables. The correlation coefficient and scatterplots of LST against NDVI were carried out using STATISTICA software based on data extracted at random points layer prepared using ArcGIS software.

\subsection{Mathematical bases of modelling}

Mathematical equations are collected and used in building eight models for calculating the values of spectral radiance, surface reflectance, albedo, NDVI, SAVI, LAI, emissivity and LST, as follows:-

\subsubsection{Spectral radiance}

The first phase of the land surface temperature calculation requires the conversion of digital number (DN) of satellite data into spectral radiance values. There are two ways of conversion; first is based on the minimum and maximum radiance of each band, taken from the metadata file according to the type of satellite sensor. This method was used in calculation of the spectral radiance of Landsat 4,5 and 7 data based on equation 1 [7]:

$$
\mathrm{L}_{\lambda}=\left(\frac{\mathrm{Lmax}_{\lambda}-\mathrm{Lmin}_{\lambda}}{\mathrm{Qcal}_{\operatorname{Max}}}\right) \times \mathrm{Q}_{\mathrm{cal}}+\mathrm{Lmin}_{\lambda}
$$

Where $\mathrm{L} \lambda$ spectral radiance $(\mathrm{W} /(\mathrm{m} 2$. sr. $\mu \mathrm{m})), \operatorname{lmin} \lambda$, $\operatorname{lmax} \lambda$ are minimum and maximum spectral radiance for each band from the metadata file, $\mathrm{Q}_{\mathrm{cal}}$ is the band digital 
number, Qcalmin= 0.0 before 2004 and 1 after 2004, Qcalmax is 255 (Landsat 7,NASA, 2011).

The second method was used to calculate the spectral radiance of Landsat 8 data according to equation 2 [8]:

$$
\mathrm{L}_{\lambda}=\mathrm{ML} \times \mathrm{Q}_{\mathrm{cal}}+\mathrm{AL}
$$

Where $M L$ and $A L$ are radiance Mult_band and Addband values from the metadata file.

\subsubsection{Surface reflectance}

To remove the errors from spectral radiance; atmospheric correction was carried out by conversion of spectral radiance to surface reflectance [7]:

$$
\begin{gathered}
\lambda=\frac{\pi\left[L_{\text {sat }}(\lambda)-L_{p}(\lambda)\right] \times d^{2}}{E_{o}(\lambda) \times \cos \left(\theta_{z}\right)} \\
\mathrm{L}_{\mathrm{p}(\lambda)}=\mathrm{L}_{\text {min }}(\lambda)-\mathrm{L}_{1 \%}(\lambda)
\end{gathered}
$$

Where $E_{o}(\lambda)=E_{S U N} \lambda=$ Exoatmospheric irradianc

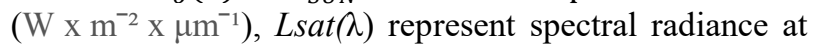
sensor, $\cos (\theta z)=$ Cosine of solar zenith angle calculated as follows:

$$
\theta=\text { solar zenith }=90 \text { - solar elevation }
$$

While $\mathrm{L}_{1 \%}(\lambda)$ is haze radiance at sensor and calculated as follows :-

$$
\begin{aligned}
& \mathrm{L}_{1 \%}(\lambda)=\frac{0.01 \times \cos \left(\theta_{\mathrm{Z}}\right)^{2} \times \mathrm{E}_{\mathrm{o}}(\lambda)}{\pi \times \mathrm{d}^{2}} \\
& \mathrm{~d}=1+0.033 \cos \left(\text { DOY } \frac{2 \pi}{365}\right)
\end{aligned}
$$

$\mathrm{d}$ is Earth-sun distance ${ }^{2}$, DOY is day of year $[9,10]$.

\subsubsection{Albedo}

The albedo of Landsat 4, 5 and 7 can be calculated according to the following equation $[11,12]$ :

$$
\begin{aligned}
& \alpha_{\mathrm{TOA}}=(0.356 \times \mathrm{b} 1+0.13 \times \mathrm{b} 3+0.373 \times \mathrm{b} 4+ \\
& 0.085 \times \mathrm{b} 5+0.072 \times \mathrm{b} 7-0.0018) \times 100
\end{aligned}
$$

Where $b 1, b 3, \ldots b 7$ is the reflectance of specific band of the sensor.

For Landsat 8 data, the value of the Albedo is calculated according to the following equation [13]:

$$
\begin{aligned}
& \alpha_{T O A}=0.356 \times r e f_{2}+0.326 \times r e f_{3}+0.138 \times r e f_{4} \\
& +0.084 \times r e f_{5}+0.056 \times r e f_{6}+0.041 \times r e f l_{7}
\end{aligned}
$$

Albedo value at top of atmosphere was converted to surface albedo as follows [10]:-

$$
\begin{gathered}
\alpha=\frac{\left(\alpha_{\mathrm{TOA}} \alpha_{\text {path-radiance }}\right)}{\tau_{\mathrm{sw}}^{2}} \\
\tau_{\mathrm{sW}}=0.75+2 \times 10^{-5} \times \mathrm{Z}
\end{gathered}
$$

Where $a$ is the surface albedo, $\tau_{\mathrm{sw}}$ is atmospheric transmissivity.

\subsubsection{Normalized Difference Vegetation Index (NDVI)}

The NDVI is an important index in calculating the land surface temperature ranging between (-1 and 1$)$, where the positive values indicate that there is a vegetation and the negative values mean the barren land [14].
Comparison of LST and NDVI values shows linear and mostly negative correlation [3]. To increase accuracy of NDVI, the values of spectral radiance are converted to atmospherically corrected reflectance values and then used to calculate the values of the NDVI [15].The following equation is used for NDVI [16]:

$$
\mathrm{NDVI}=(\mathrm{NIR}-\mathrm{RED}) /(\mathrm{NIR}+\mathrm{RED})
$$

Where NIR is the reflectance at near infrared band and RED is the reflectance at red band.

\subsubsection{Soil Adjusted Vegetation Index (SAVI)}

Because of reflectivity properties of soil and their interaction with vegetation cover added to that the chemical characteristics of soil including metallic, chemical composition, percentage of organic matter, surface roughness, tissue and moisture content of soil, therefore, the SAVI need to be calculated [17], and calculated as follows [18]:

$$
\text { SAVI }=\frac{(1+\mathrm{L}) \times(\text { TIR-RED })}{(\mathrm{L}+\mathrm{TIR}+\mathrm{RED})}
$$

Where $\mathrm{L}$ is calibration factor equal to 0.5 [10].

\subsubsection{Leaf Area Index (LAI)}

Leaf area index is calculated as follows [10]:

$$
\mathrm{LAI}=-(1 / \mathrm{a} 2) * \ln (\mathrm{a} 0-\mathrm{SAVI} / \mathrm{a} 1)
$$

Where $\mathrm{a} 0, \mathrm{a} 1, \mathrm{a} 2$ are constants calculated to be suitable with study area using calibration method [13].

\subsubsection{Emissivity}

The values of vegetation indices are used to calculate surface emissivity, which is defined as the ability of the object or surface to emit radiation compared to the black body at the same temperature [19]. Emissivity can vary greatly depending on the type, intensity and stage of vegetation growth [20]. There is more than one method to calculate the values of surface emissivity according to the variables or boundary conditions used in the selection of the emissivity value. One of the methods; depend on the values of the albedo, NDVI and LAI according to the following equations:

$$
\varepsilon=1.009+0.047 \times \ln (N D V I)
$$

If LAI is less than 3 then the following equation is used:

$$
\varepsilon=0.97+0.0033 \times L A I
$$

If LAI is greater than or equal to 3 , the emissivity is 0.98 , whereas if NDVI is less than 0 and albedo is less than 0.47 , the emissivity is $0.99[10,13,21]$.

Another method depends on the NDVI values of vegetation cover and soil and considered boundary conditions, if the value of NDVI is less than 0.2 , it means that the surface is free of vegetation cover and the emissivity value is 0.97 , but if the value of NDVI is greater than 0.5 , the value of emissivity is 0.99 , while if the NDVI value is between 0.2 and 0.5 , the emissivity value is measured from the following equation [22]:-

$$
\varepsilon=\varepsilon_{\mathrm{v}} \times \mathrm{p}_{\mathrm{v}}+\varepsilon_{\mathrm{s}}\left(1-\mathrm{p}_{\mathrm{v}}\right)+\mathrm{d}_{\varepsilon}
$$


Where $\varepsilon$ is emissivity, $\varepsilon \mathrm{v}$ emissivity of vegetation cover, $\varepsilon S$ is emissivity of soil, $d \varepsilon$ is the effect of internal reflections and geometric distribution of natural surfaces, $P v$ vegetation cover proportion [22].

$$
\begin{aligned}
& \mathrm{d}_{\varepsilon}=\left(1-\varepsilon_{\mathrm{s}}\right) \times\left(1-\mathrm{p}_{\mathrm{v}}\right) \times \mathrm{F} \times \varepsilon_{\mathrm{v}} \\
& \mathrm{p}_{\mathrm{v}}=\left[\frac{\mathrm{NDVI}-\mathrm{NDVI}_{\min }}{N D V I_{\max }-N D V I_{\min }}\right]^{2}
\end{aligned}
$$

\subsubsection{Brightness temperature (Tc)}

To calculate LST from the thermal bands of Landsat satellite sensor; first, the brightness temperature (Tc) or black body temperature on board of the satellite needs to be calculated as follows $[7,23,24]$ :

$$
\mathrm{T}_{\mathrm{c}}=\frac{\mathrm{K} 2}{\ln \left(\frac{\mathrm{K} 1}{\mathrm{~L} \lambda}+1\right)}
$$

Where $\mathrm{K} 1$ and $\mathrm{K} 2$ are constants as given in Table 1, $\mathrm{L} \lambda$ is spectral radiance of thermal band.

Table 1. Constants of Landsat satellite sensors.

\begin{tabular}{|c|c|c|}
\hline Satellite & K1 & K2 \\
\hline LANDSAT_4 (TM) & 671.62 & 1284.30 \\
\hline $\begin{array}{c}\text { LANDSAT_7 } \\
\text { (ETM+) }\end{array}$ & 666.09 & 1282.71 \\
\hline $\begin{array}{c}\text { LANDSAT_8 } \\
\text { (OLI_TIRS) }\end{array}$ & $\begin{array}{c}\mathrm{b} 10=774.8854 \\
\mathrm{~b} 11=480.8883\end{array}$ & $\begin{array}{c}\mathrm{b} 10=1321.0789 \\
\mathrm{~b} 11=1201.1442\end{array}$ \\
\hline
\end{tabular}

Source: USGS, Landsat scene metadata file.

\subsubsection{Land Surface Temperature (LST)}

The land surface temperature is calculated from the brightness temperature or black body temperature corrected according to the emissivity values of the different land use/land cover classes, based on the following equation $[2,21,23]$ :

$$
\mathrm{T}_{\mathrm{s}}=\frac{\mathrm{T}_{\mathrm{c}}}{1+\left(\lambda \times \mathrm{T}_{\mathrm{c}} / \rho\right) \times \ln \varepsilon}
$$

Where $\lambda$ is average wavelength of thermal band, $\rho$ is constant equal to $0.01438 \mathrm{~m}$. kelvin and calculated based on $a$ Boltzmann constant, $h$ Blank constant, $c$ is velocity of light [2]:

$$
\begin{gathered}
\rho=\mathrm{h} \times \mathrm{c} / \mathrm{a} \\
\text { LST in kelvin is converted to Celsius as follows }{ }^{3} \text { : } \\
\mathrm{T}\left({ }^{\circ} \mathrm{C}\right)=\mathrm{T}(\mathrm{K})-273.15
\end{gathered}
$$

\section{Results and discussion}

The spatial variations of LSTs and land use/land cover (LULC) types are illustrated in distribution maps. During the four periods; LULC are classified into seven types i.e., water bodies (River, Lake, Swamps), cropland, grass and garden, green land (Orchards), bare land, residential area and roads and parks. The statistics of LSTs are summarised according to LULC as shown in Table 2. The results extracted from Landsat 4 TM image acquired on July 16, 1989 (Fig. 2), show that the lowest average LST about $30.6{ }^{\circ} \mathrm{C}$ was recorded on water bodies (River, Lake, and Swamps), followed by vegetation cover
(Cropland, Grass and Garden, and Green land) with average LST ranging from 32.7 to $37.3{ }^{\circ} \mathrm{C}$, while the highest LST was recorded at barren land (Bare land, residential area, roads and parks) with average values ranging from 38.8 to $40.6{ }^{\circ} \mathrm{C}$ and covered about $76.7 \%$ of study area, while the vegetation cover was covered about $20.8 \%$ of the area and most of them are extended along Tigris River. The LSTs measured from Landsat 7 ETM+ image acquired on April 25, 2000 (Fig. 3), show a decline in temperature of all classes. In fact, the water bodies recorded low temperature of about $21.3{ }^{\circ} \mathrm{C}$, meanwhile, the vegetation cover gives LST ranging from 26.3 to $29.4{ }^{\circ} \mathrm{C}$ with approximately the same coverage area of about $21.7 \%$. The barren lands including a residential area, roads, and parks are covered about $76.3 \%$ of the area and their average LSTs ranging from 30.7 to $33.2{ }^{\circ} \mathrm{C}$ with a relatively high standard deviation of LSTs at roads and parks class, because of mixed pixels with other classes. Also, the study area witnesses an increase in the percentage of built-up area (Residential area, roads and parks) $45 \%$ during 1989 up to $50.4 \%$ that means increase of impervious surfaces which makes the city canopy to be warmer. On April 26, 2006, Landsat 7 ETM+ image was analyzed for LSTs over the study area (Fig. 4), the results show that water bodies still covering about $2.7 \%$ with average LSTs $19.4^{\circ} \mathrm{C}$, while vegetation cover remains about $20.6 \%$ of the area with average LSTs ranging from 23.6 to $26.7{ }^{\circ} \mathrm{C}$, barren lands cover about $76.7 \%$ of the area with average LSTs ranging from 26.1 to $26.8^{\circ} \mathrm{C}$, meanwhile, built up area (Residential area, roads and parks) are continued to increase among other land use classes and reached up to $54.5 \%$. The results of latest analysis of LSTs from Landsat 8 (OLI_TIRS) image acquired on May 31, 2016 (Fig. 5 and Table 2) was carried out based on thermal bands i.e., b10, b11 and average values of the two bands. The achieved results of LSTs are compared with in-situ measurements carried out on different land use/land cover types during June 24, 2016, at time 10.50-11.20 am listed as $35{ }^{\circ} \mathrm{C}$ at building shadow, $42{ }^{\circ} \mathrm{C}$ at building roofs, $40{ }^{\circ} \mathrm{C}$ at road pavement, $37{ }^{\circ} \mathrm{C}$ at vegetation cover and $28{ }^{\circ} \mathrm{C}$ at river water. The comparison of in-situ measurements and calculated LSTs; indicates the LSTs measured from b10 and b11 are deviated from in-situ measurement, but they are more comparable with LSTs calculated from average b10 and b11. The LULC classification results indicate the vegetation cover was reduced to $15.3 \%$ of study area while barren lands increased up to $82.5 \%$ at the same time; residential area witness dramatic increase up to $62.5 \%$ compared to $31.8 \%$ at 1989 , the roads network and parks are reduced to $5.1 \%$ because of low maintenance which led to making their spectral signatures mixed with residential area and lost their sharp contrast which was recognized during 1989. In fact, the increase in barren lands especially residential area will lead to rising LSTs and the local climate being prone to be warmer during the summer season. To show the relation between LSTs and vegetation cover; scatterplots of LST against NDVI were plotted and the correlation was measured as shown in scatterplots in Figure 6 , the regression lines during the studied periods 
show inverse correlation between LST and NDVI and the correlation coefficient values ranging from -0.54 to -0.81 , indicating the importance of vegetation cover as the main factor of land use in reducing the LST in study area. Indeed, the lack of interest in increasing and enlarging tree cover and landscaping in the study area will make the city suffer from warm local climate.

Table 2. Statistical parameters of LST of different LULC classes.

\begin{tabular}{|c|c|c|c|c|}
\hline \multicolumn{5}{|c|}{16 July 1989} \\
\hline $\begin{array}{c}\text { Land use/ land cover } \\
\text { type }\end{array}$ & $\begin{array}{c}\text { Area } \\
\left(\mathbf{k m}^{2}\right)\end{array}$ & $\%$ area & $\begin{array}{c}\text { Avg. T. } \\
\left({ }^{\circ} \mathbf{c}\right)\end{array}$ & $\begin{array}{r}\text { SD. T. } \\
\left({ }^{\circ} \mathbf{c}\right)\end{array}$ \\
\hline River, lake \& swamps & 8.9 & 2.5 & 30.6 & 3.2 \\
\hline Crop land & 10.3 & 2.8 & 33.9 & 1.8 \\
\hline Grass \& garden & 51.5 & 14.2 & 37.3 & 2.0 \\
\hline Green land (Orchards) & 13.7 & 3.8 & 32.7 & 1.5 \\
\hline Bare land & 114.6 & 31.7 & 40.6 & 1.5 \\
\hline Residential area & 114.8 & 31.8 & 38.8 & 1.5 \\
\hline Roads \& parks & 47.7 & 13.2 & 38.8 & 1.8 \\
\hline \multicolumn{5}{|c|}{26 April 2006} \\
\hline River, lake \& swamps & 9.64 & 2.7 & 19.4 & 2.2 \\
\hline Crop land & 2.85 & 0.8 & 23.6 & 1 \\
\hline Grass \& garden & 48.27 & 13.3 & 26.7 & 1.6 \\
\hline Green land (Orchards) & 23.35 & 6.5 & 24.9 & 1.5 \\
\hline Bare land & 80.46 & 22.2 & 26.8 & 1.2 \\
\hline Residential area & 140.9 & 39 & 26.1 & 1.1 \\
\hline Roads \& parks & 56.12 & 15.5 & 26.1 & 1.5 \\
\hline \multicolumn{5}{|c|}{$\begin{array}{r}25 \text { April } 2000 \\
\end{array}$} \\
\hline River, lake \& swamps & 7.3 & 2 & 21.3 & 1.05 \\
\hline Crop land & 4.4 & 1.2 & 26.76 & 1.58 \\
\hline Grass \& garden & 53.6 & 14.8 & 29.36 & 1.67 \\
\hline Green land (Orchards) & 20.6 & 5.7 & 26.27 & 1.56 \\
\hline Bare land & 93.8 & 25.9 & 33.16 & 1.85 \\
\hline Residential area & 155.4 & 43 & 31.14 & 1.63 \\
\hline Roads \& parks & 26.6 & 7.4 & 30.67 & 2.23 \\
\hline \multicolumn{5}{|c|}{ 31 May 2016 from band 10} \\
\hline River, lake \& swamps & 7.73 & 2.1 & 30.9 & 2.4 \\
\hline Crop land & 4.15 & 1.1 & 36.2 & 2.2 \\
\hline Grass \& garden & 44.61 & 12.3 & 40.2 & 2.2 \\
\hline Green land (Orchards) & 6.81 & 1.9 & 36.1 & 2.6 \\
\hline Bare land & 53.47 & 14.8 & 42.7 & 1.6 \\
\hline Residential area & 225.9 & 62.5 & 41.3 & 1.2 \\
\hline Roads \& parks & 18.88 & 5.2 & 40.9 & 2.7 \\
\hline \multicolumn{5}{|c|}{31 May 2016 from band 11} \\
\hline River, lake \& swamps & 7.73 & 2.1 & 25.6 & 1.9 \\
\hline Crop land & 4.15 & 1.1 & 29.7 & 1.7 \\
\hline Grass \& garden & 44.61 & 12.3 & 32.8 & 1.7 \\
\hline Green land (Orchards) & 6.81 & 1.9 & 29.6 & 2.0 \\
\hline Bare land & 53.47 & 14.8 & 34.7 & 1.2 \\
\hline Residential area & 225.9 & 62.5 & 33.7 & 0.95 \\
\hline Roads \& parks & 18.88 & 5.2 & 33.4 & 2.1 \\
\hline \multicolumn{5}{|c|}{31 May 2016 from Avg. b10 \&b11 } \\
\hline River, lake \& swamps & 7.73 & 2.1 & 28.31 & 2.21 \\
\hline Crop land & 4.15 & 1.1 & 33.04 & 1.95 \\
\hline Grass \& garden & 44.61 & 12.3 & 36.55 & 1.95 \\
\hline Green land (Orchards) & 6.81 & 1.9 & 32.88 & 2.32 \\
\hline Bare land & 53.47 & 14.8 & 38.78 & 1.43 \\
\hline Residential area & 225.9 & 62.5 & 37.58 & 1.08 \\
\hline Roads \& parks & 18.88 & 5.2 & 37.17 & 2.41 \\
\hline
\end{tabular}

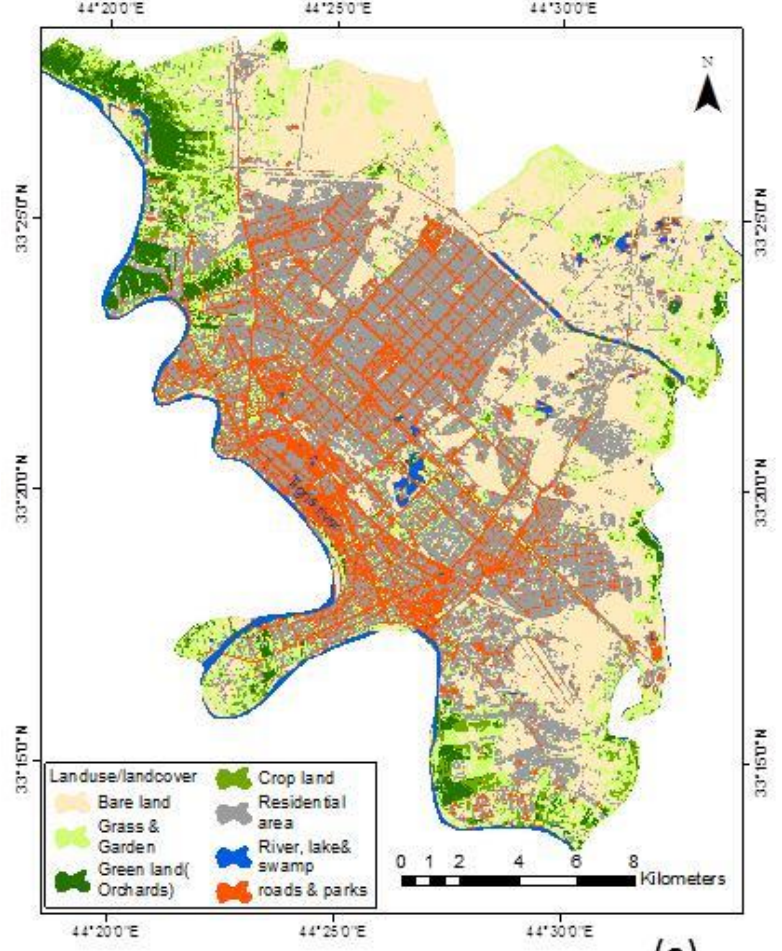

(a)

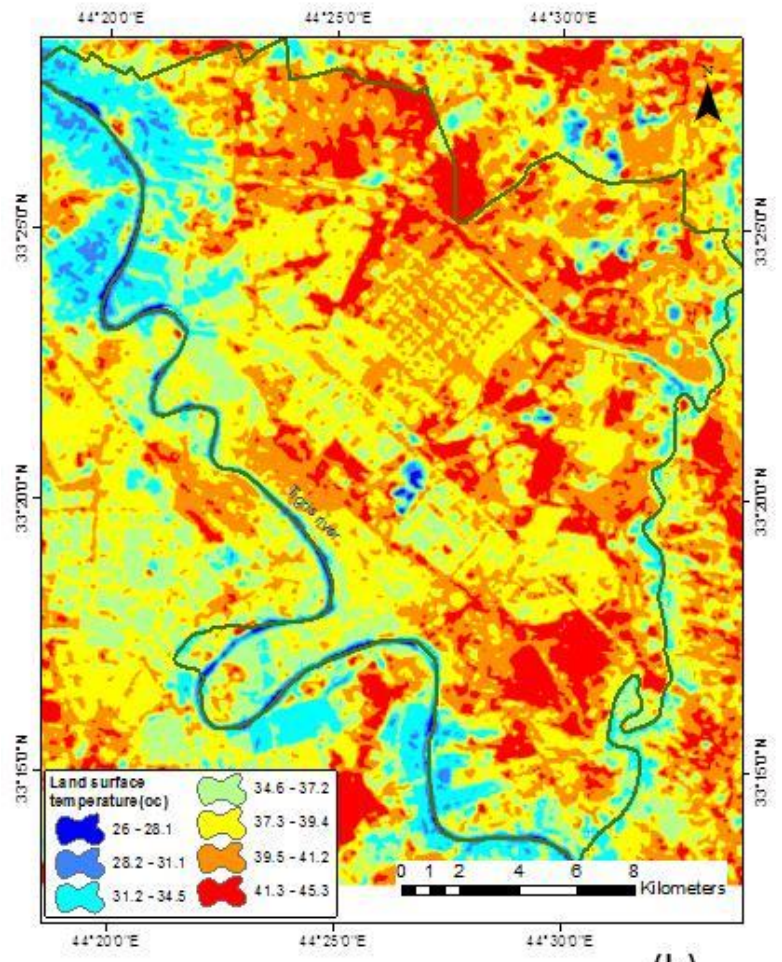

(b)

Fig. 2. Land use/land cover map during 16 July 1989: a). LULC, b). LSTs 


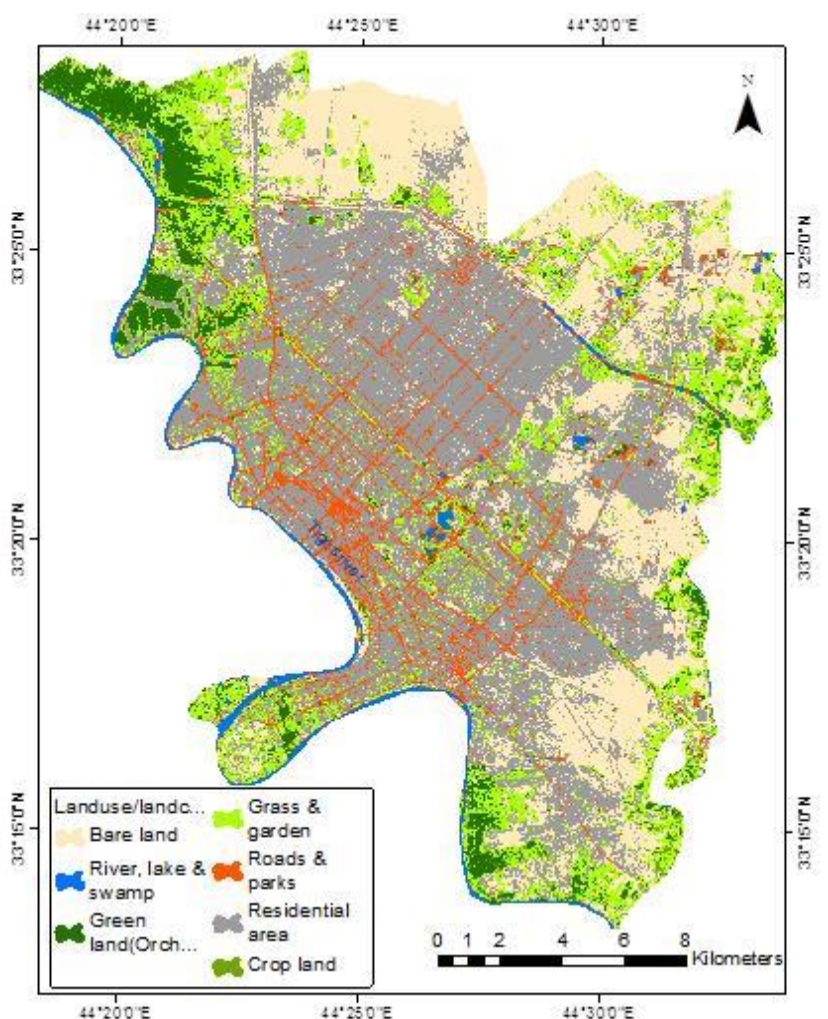

(a)

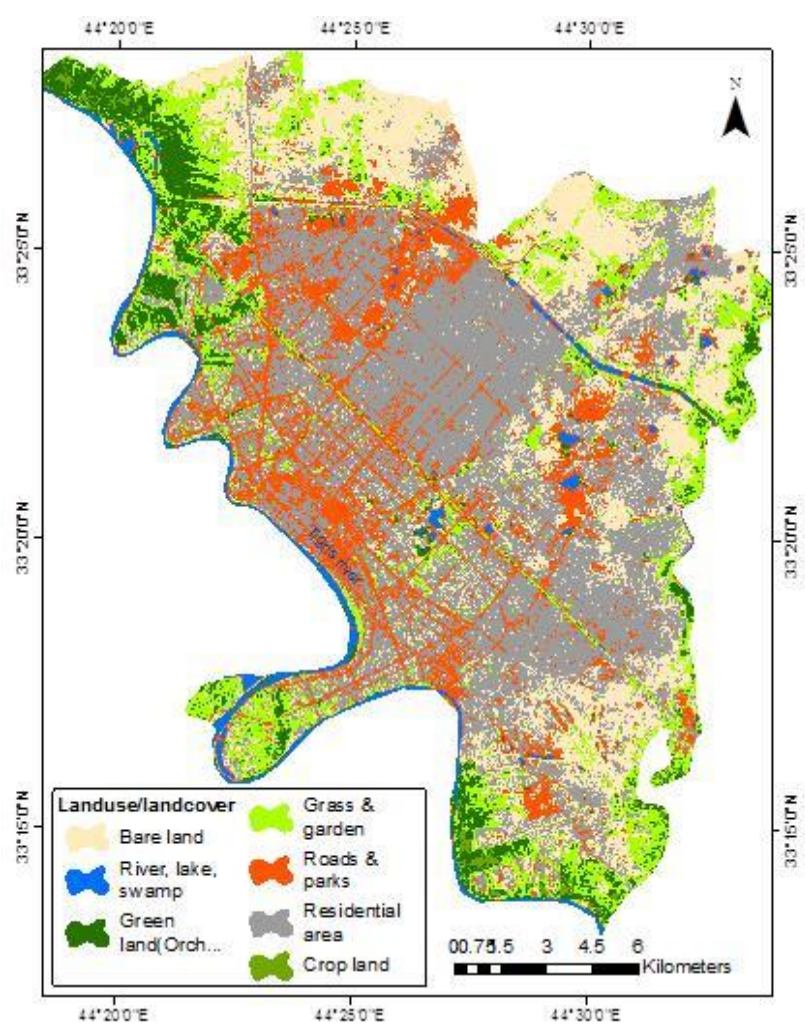

(a)

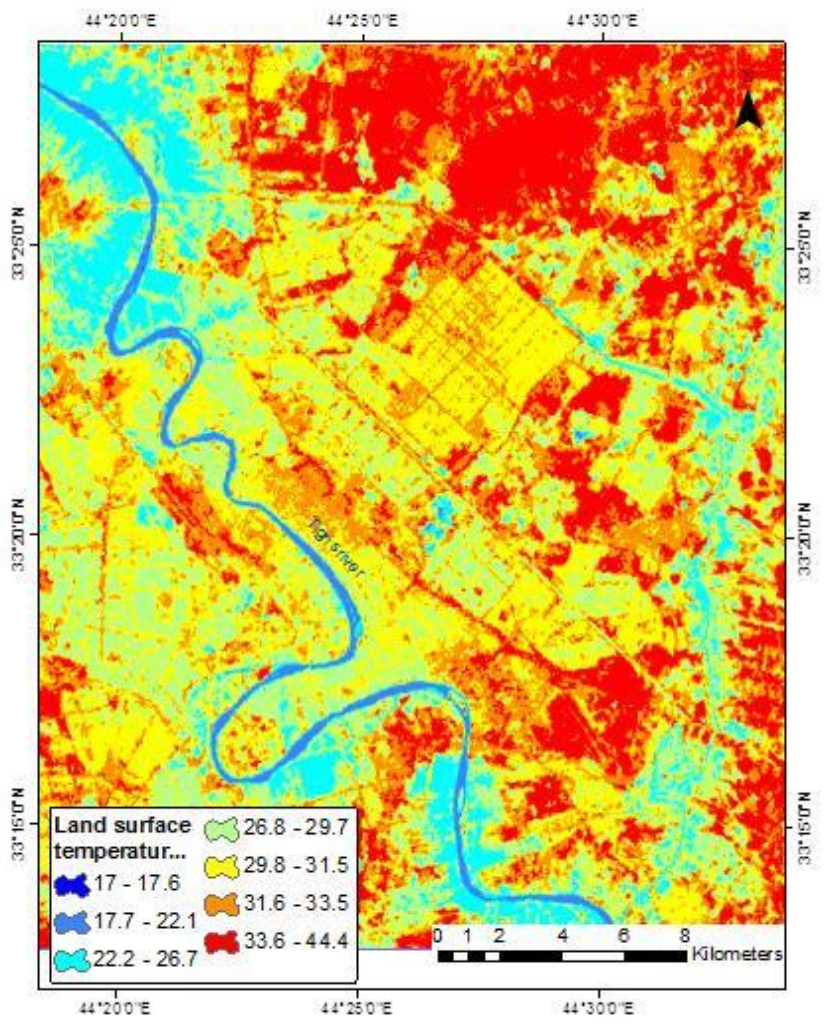

(b)

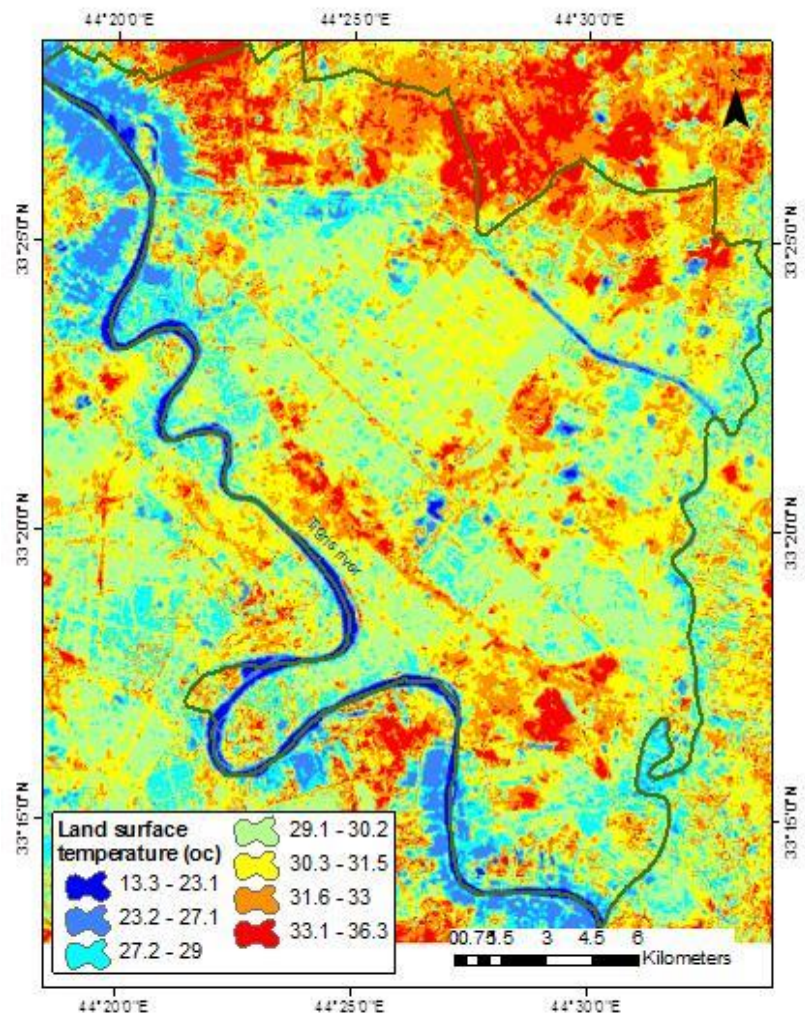

(b)

Fig. 3. Distribution maps during 25 April 2000: a).LULC, b). LSTs

Fig. 4. Distribution maps during 26 April 2006:a). LULC, b). LSTs. 


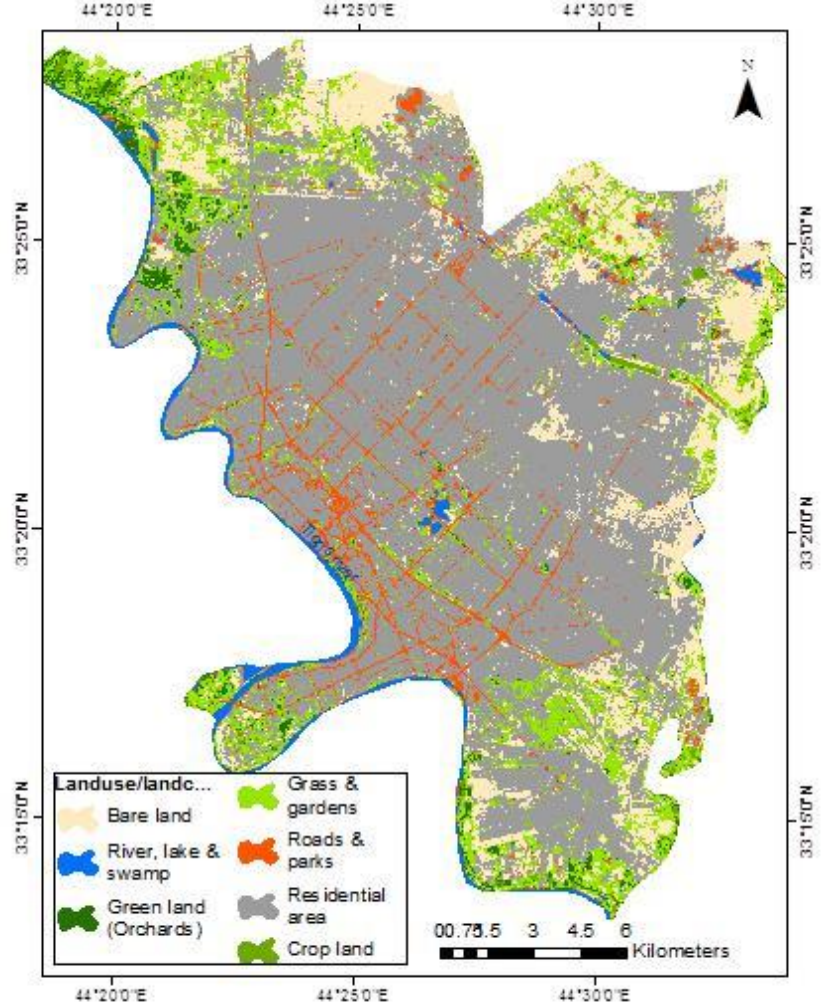

(a)

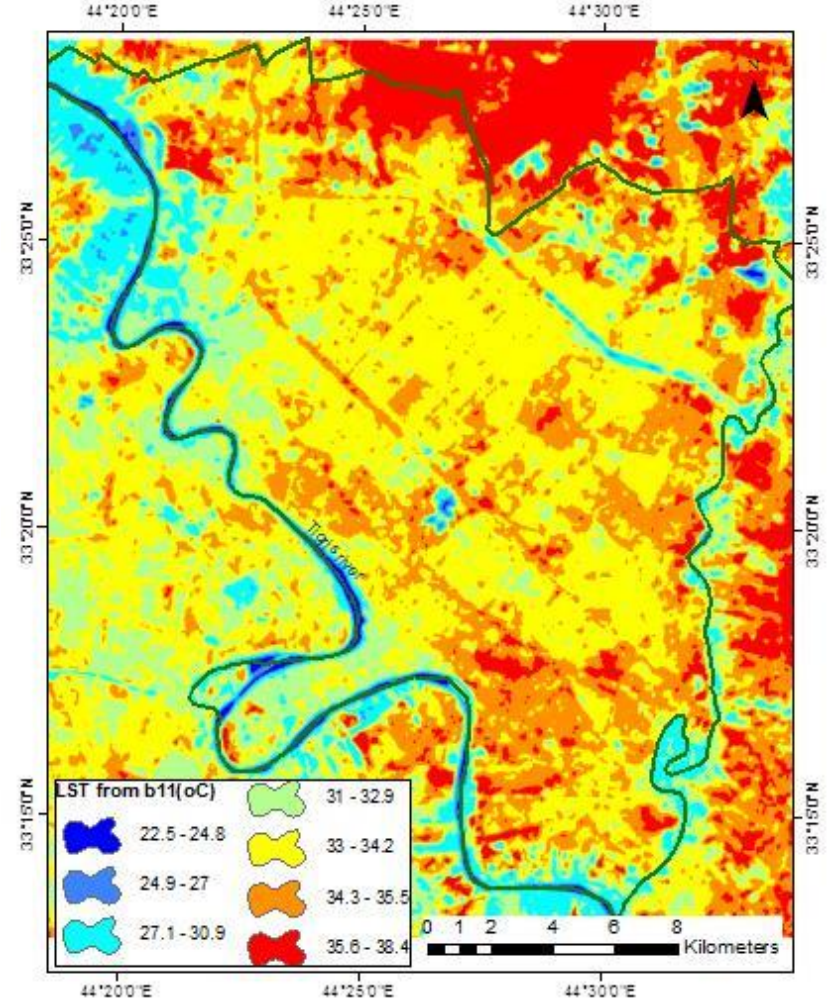

(c)

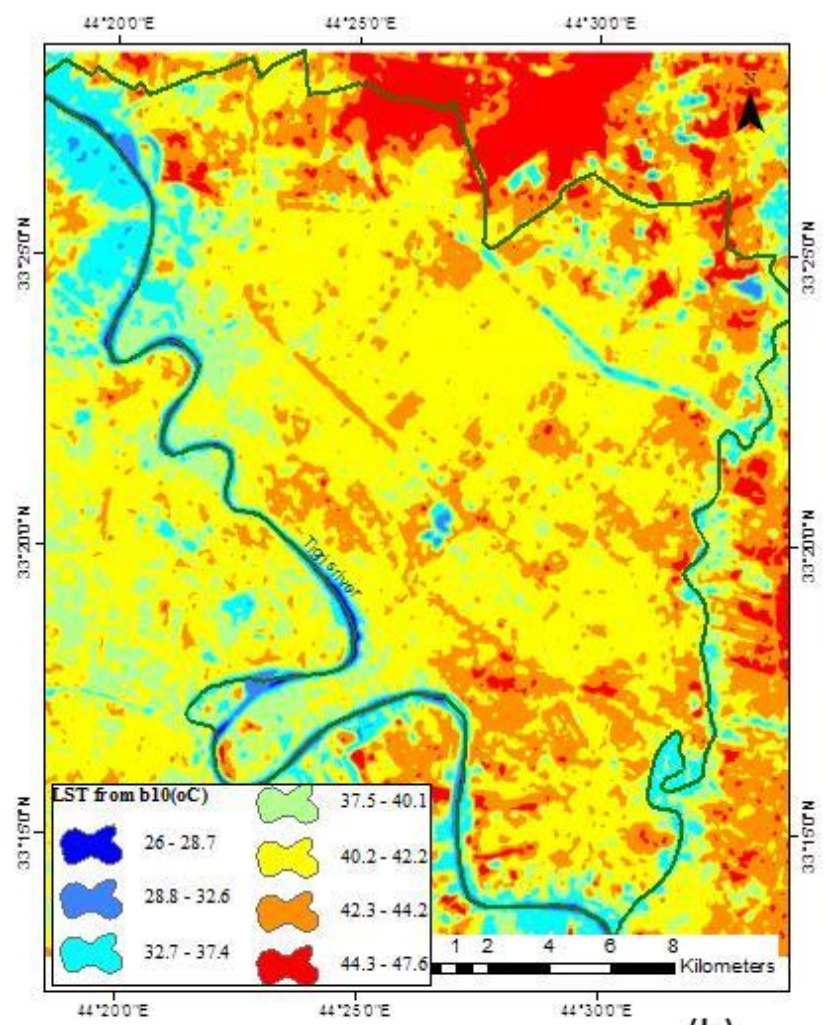

(b)

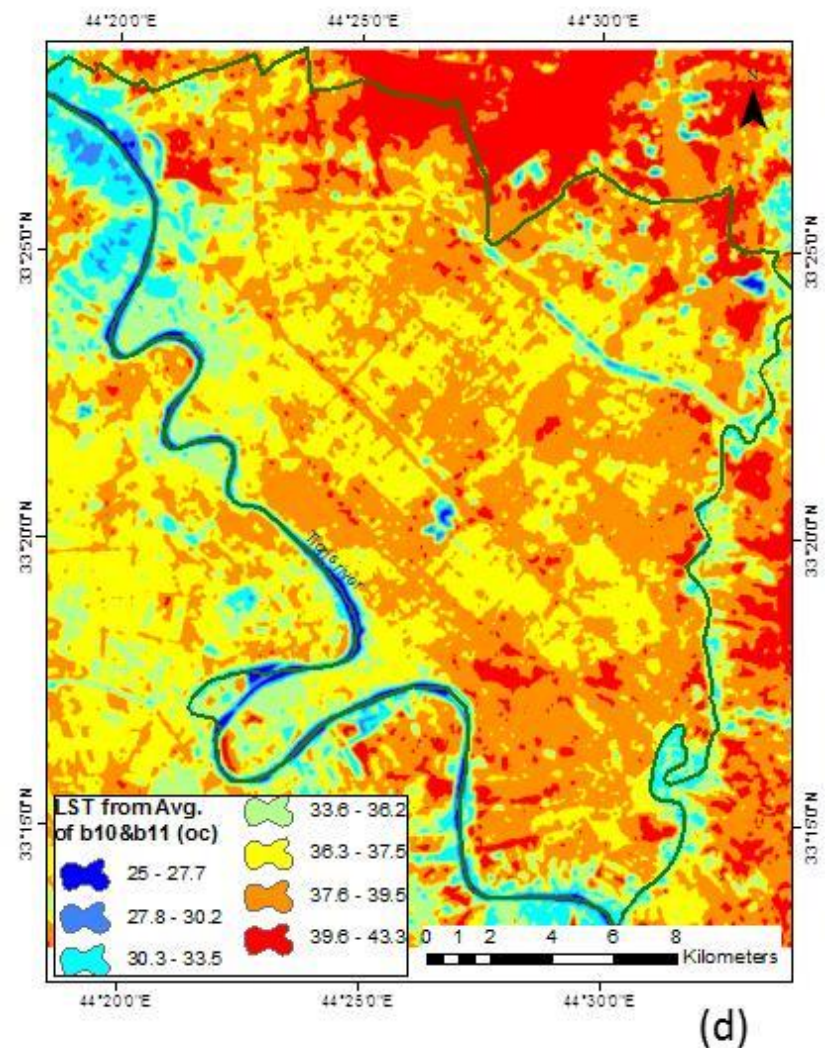

Fig. 5. Continued
Fig. 5. Distribution maps during 31 May 2016: a). LULC, b). LSTs. from B10., c). LSTs. from B11 and d). LSTs. From average of $\mathrm{B} 10 \& \mathrm{~B} 11$. 


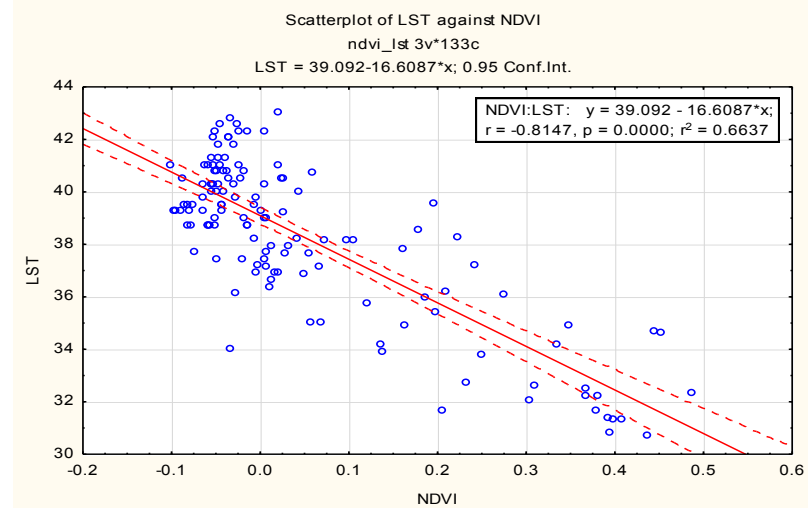

16 July 1989

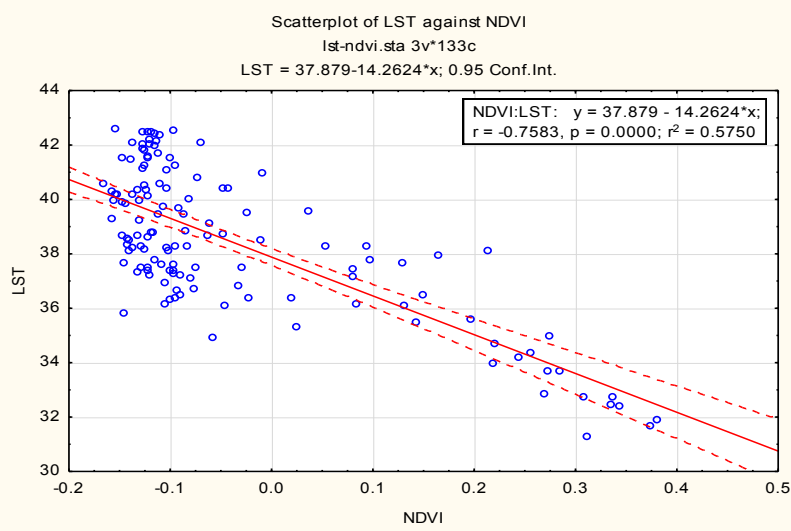

26 April 2006

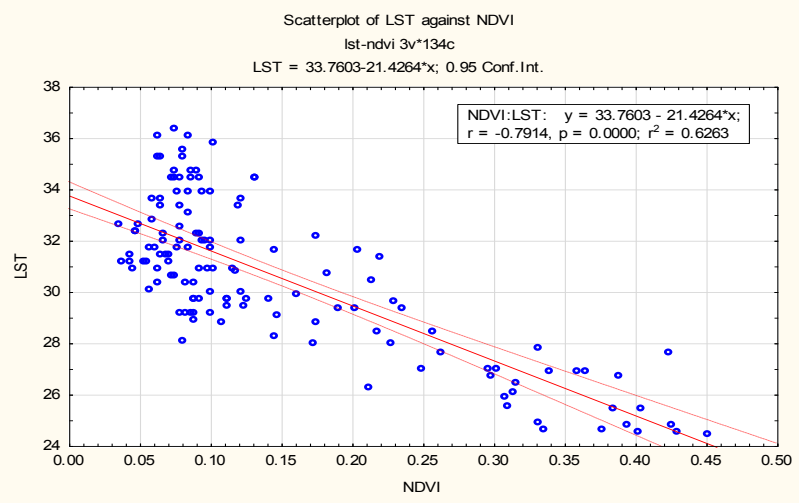

25 April 2000

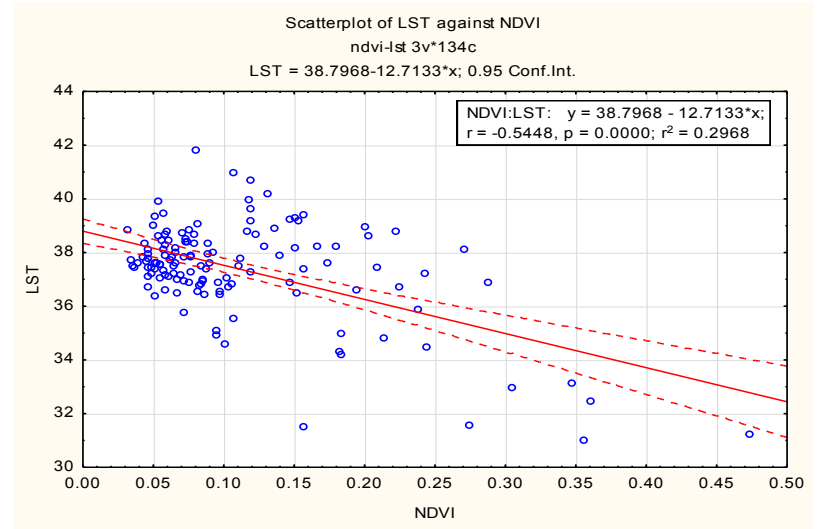

31 May 2016

Fig. 6. Scatterplots of LST against NDVI.

\section{Conclusions}

The analysis of the LSTs and LULC relationship shows that there are two main land use/ land cover controlling the spatial distribution of LSTs in study area i.e., barren lands (built up area and bare lands) and vegetation cover density. Based on the results, the vegetation cover area shows temperature difference of $3-5^{\circ} \mathrm{C}$ less than barren lands during the study period, indicating their positive impact on reducing LST in the study area. The orchards area are the most important vegetation cover in the city for reducing the LSTs, in Rusafa side of Baghdad city the percentage of orchards did not exceed $6 \%$ of the study area during 1989 , even this percent was reduced to $2 \%$ on 2016. While the residential area increased dramatically from $32 \%$ during 1989 up to $62 \%$ during 2016 resulting in increase in impervious surfaces and pavement areas which consequently lead to rising of LSTs of the city. Roads network faced low maintenance resulting in difficulty in differentiating them from the residential area during digital classification of the images that is clear from comparison of roads extracted from an image acquired during 1989 and that acquired during 2016. The LST and NDVI are correlated inversely with correlation coefficient ranging from -0.54 to -0.81 . For Landsat 8; the LSTs measured from average of b10 and b11 is more correlated with the measurement of temperature in-situ.

The author would like to record his thanks to Mustansiriyah University for the encouragement for completion and publishing of this work.

\section{References}

1. Rolf A. D., Principles of Geographic Information Systems: An Introductory Textbook. Vol. 1 (International Institute for Geo-Information Science and Earth Observation, 2004)

2. Weng Q., Remote Sensing and GIS Integration: Theories, Methods, and Applications (McGraw-Hill New York, 2010)

3. Quattrochi D. A. J. C. Luvall, Thermal Remote Sensing in Land Surface Processing. (CRC Press, 2004)

4. G. D. Jenerette, S. L. Harlan, A. Buyantuev, W. L. Stefanov, J. Declet-Barreto, B. L. Ruddell, S. W. Myint, S. Kaplan, and X. Li,. L. Ecol. 31, 4, 745 (2015)

5. J. E. Nichol, J. Appl. Meteo. 35, 1, 135 (1996)

6. Parris J. K. M. Parris, Ecology of Urban Environments (John Wiley \& Sons, 2016)

7. G. Chander and B. Markham. IEEE Trans. Geos. R.S. 41, 11, 2674 (2003)

8. Usgs, Landsat 8 (L8) Data Users Handbook. (2ed. Lsds-1574, EROS Sioux Falls, South Dakota: USGS, 2016)

9. Allen R. G. L. S. Pereira, D. Raes, and M. Smith, Crop Evapotranspiration-Guidelines for Computing Crop Water Requirements-Fao Irrigation and 
Drainage Paper 56 (FAO, Rome. 300, 9, D05109, 1998)

10. Waters R. R. Allen, W. Bastiaanssen, M. Tasumi, and R. Trezza, Sebal. Surface Energy Balance Algorithms for Land (Idaho, USA, 2002)

11. Mohamed M., Summer Land Surface Temperature: Small-Local Variation in Intro-Urban Environment in El Paso (U. of Texas, El Paso, Tx. 2013)

12. S. Liang, R. S. of Env. 76, 2, 213 (2001)

13. A. A. F. Beg, A. H. Al-Sulttani, A. Ochtyra, A. Jarocińska, and A. Marcinkowska, J. Geo. Res. E. 6, 257 (2016)

14. F. Yuan, and M. E. Bauer, R. S. of Env. 106, 3, 375 (2007)

15. X. Yu, X. Guo, and Z. Wu, R. S., 6, 9829 (2014)

16. Lillesand T. R. W. Kiefer, and J. Chipman, Remote Sensing and Image Interpretation. (John Wiley \& Sons, 2014)

17. E. R. Stoner, M. F. Baumgardner, R. A. Weismiller, L. L. Biehl, and B. F. Robinson, S. Sci. Soc. of A. J., 44, 3, 572 (1980)

18. A. R. Huete, R. S. of Env., 25, 3, 295 (1988)

19. Watson C., Analysis of Urban Heat Island Climates Along the I-85/I-40 Corridor in Central North Carolina. (U. of North Carolina, Greensboro, 2012)

20. Q. Weng, J. of Photo. and R. S., 64, 4, 335 (2009)

21. A. Faris, and Y. S. Reddy, IJEE., 3, 3, 332 (2010)

22.A. Asgarian, B. J. Amiri, and Y. Sakieh, U. Ecos., 18, 1, 209 (2014)

23. Q. Weng, D. Lu, and J. Schubring, R. S. of Env., 89, 4, 467 (2004)

24. J. Li, C. Song, L. Cao, F. Zhu, X. Meng, and J. Wu, R. S. of Env., 115, 12, 3249 (2011) 